\title{
CYP1A1, CYP2E1 and GSTM1 genetic polymorphisms. The effect of single and combined genotypes on lung cancer susceptibility in Chilean people
}

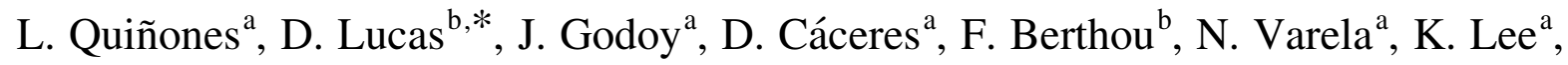 \\ C. Acevedo ${ }^{\mathrm{a}}$, L. Martínez ${ }^{\mathrm{a}}$, A.M. Aguilera ${ }^{\mathrm{a}}$, L. Gil $^{\mathrm{a}}$ \\ ${ }^{\mathrm{a}}$ Faculty of Medicine, Laboratory of Environmental Toxicology and School of Public Health, University of Chile, Santiago, Chile \\ ${ }^{\mathrm{b}}$ Faculty of Medicine, Laboratory. Biochimie-Nutrition EA948, B.P. 29285 Brest, France
}

Received 23 March 2001; received in revised form 10 July 2001; accepted 12 July 2001

\begin{abstract}
CYP1A1, CYP2E1 and GSTM1 polymorphisms were evaluated in Chilean healthy controls and lung cancer patients. In the Chilean healthy group, frequencies of CYP1A1 variant alleles for $M s p I(\mathrm{~m} 2$ or $C Y P 1 A 1 * 2 A)$ and ile/val (val or CYP1A1*2B) polymorphisms were 0.25 and 0.33 , respectively. Frequencies of variant alleles $C(C Y P 2 E 1 * 6)$ and $\mathrm{c} 2(C Y P 2 E 1 * 5 B)$ for $C Y P 2 E 1$ were 0.21 and 0.16 , respectively and frequency for $G S T M 1(-)$ was 0.24 . The presence of variant alleles for GSTM1, MspI and Ile/val polymorphisms was more frequent in cases than in controls. However, frequencies for the c2 and $\mathrm{C}$ alleles were not significantly different in controls and in cases. The estimated relative risk for lung cancer associated to a single mutated allele in CYP1A1, CYP2E1 or GSTM1 was 2.41 for m2, 1.69 for val, 1.16 for C, 0.71 for c2 and 2.46 for GSTM1(-). The estimated relative risk was higher for individuals carrying combined CYP1A1 and GSTM1 mutated alleles $(\mathrm{m} 2 / \mathrm{val}, \mathrm{OR}=6.28 ; \mathrm{m} 2 / G S T M 1(-), \mathrm{OR}=3.56)$ and lower in individuals carrying CYP1A1 and CYP2E1 mutated alleles $(\mathrm{m} 2 /$ $\mathrm{C}, \mathrm{OR}=1.39 ; \mathrm{m} 2 / \mathrm{c} 2, \mathrm{OR}=2.00 ; \mathrm{val} / \mathrm{C}, \mathrm{OR}=1.45 ; \mathrm{val} / \mathrm{c} 2, \mathrm{OR}=0.48 ;$ not significant). The $\mathrm{OR}$ values considering smoking were 4.37 for $\mathrm{m} 2,4.05$ for val, 3.47 for $\operatorname{GSTMI}(-)$, 7.38 for m2/val and 3.68 for $\mathrm{m} 2 / G S T M 1(-)$, higher values than those observed without any stratification by smoking. Taken together, these findings suggest that Chilean people carrying single or combined GSTM1 and CYP1A1 polymorphisms could be more susceptible to lung cancer induced by environmental pollutants such as polycyclic aromatic hydrocarbons. (C) 2001 Elsevier Science Ireland Ltd. All rights reserved.
\end{abstract}

Keywords: CYP1A1; CYP2E1; GSTM1; Polymorphisms; Lung cancer risk; Molecular epidemiology

\section{Introduction}

Polycyclic aromatic hydrocarbons (PAHs) present in smoked foods, tobacco smoke and ubiquitous in

\footnotetext{
* Corresponding author. Laboratory of Biochemistry-EA948, Faculty of Medicine, 22, Avenue C. Desmoulins, BP-815 - 29285 Brest Cedex, France. Tel.: +33-2-98-016-465; fax: +33-2-98-016603.

E-mail address: daniele.lucas@univ-brest.fr (D. Lucas).
}

urban environments in large cities, are believed to be responsible for an elevated risk in certain cancers, specially lung cancer. PAHs are metabolized to reactive DNA binding diol epoxides by phase I enzymes cytochrome P4501A1 (CYP1A1) and detoxified by phase II enzymes, including glutathione S-transferase (GSTM1) [1,2] before reaching their target. It is possible that individual variations in metabolic activities in each phase or in the coordination of these two phases regulate the clearance of DNA toxic metabolites and 
might be partially responsible for individual host susceptibility to PAHs exposure-related cancer.

CYP1A1 is an enzyme with aryl hydrocarbon hydroxylase activity (AHH). CYP1A1 high activity has been shown to be associated with high lung cancer risks [3-5], The entire CYPIAl gene has been sequenced [6] and two separate point mutations have been reported: one in the $3^{\prime}$ - non-coding region, MspI polymorphism ${ }^{1}$ [7] and the other within exon 7, ile/val polymorphism [8]. More recently, two other CYP1A1 polymorphisms have been reported, $\mathrm{m} 3$ allele $^{1}$ also in the $3^{\prime}$-flanking region which seems to be specific to people of African descent $[9,10]$ and $m 4$ allele ${ }^{1}$ located in exon 7 , that exchanges threonine 461 with asparagine and that has been found present in German, Polish and Turkish populations [11,12]. Though the relationship of these mutations with AHH inducibility has not been fully established $[4,5]$, it has been suggested that homozygotes of variant allele of each mutation are correlated with an enhanced susceptibility to lung cancer, specially in Japanese smokers [7]. However, contradictory data have been published on this topic and a recent meta-analysis by Houlston et al. [13] did not show significant associations between CYP1A1 genetic polymorphisms and lung cancer.

On the other hand, CYP2E1 has been proposed as a possible cancer marker enzyme due to its activity toward several carcinogenic xenobiotics as for example ethanol, benzene, N-nitrosodimethylamine, styrene, butadiene and urethane [14-17]. Two point mutations have been identified upstream of the CYP2E1 gene in the regulatory elements which are completely linked (RsaI and PstI) ${ }^{1}$. Other mutations have been identified within intron 6 of the gene $(\text { DraI })^{1}[18]$.

GSTM1 is one of the enzymes belonging to a family of glutathione transferases that is polymorphic with a deficient activity in approximately $50 \%$ of the Caucasian population [19]. Lack of this detoxification activity has been demonstrated to be caused by an

\footnotetext{
${ }^{1}$ According to the recommended nomenclature of the human polymorphic genes, $C Y P 1 A 1$ wild type allele: $C Y P 1 A 1 * 1 A ; M s p I$ or $m 2$ allele: $C Y P 1 A 1 * 2 A$; Val allele: $C Y P 1 A 1 * 2 B ; C Y P 1 A 1 \mathrm{m3}$ allele: $C Y P 1 A 1 * 3 \quad C Y P 1 A 1 \mathrm{~m} 4$ allele: $C Y P 1 A 1 * 4 ; C Y P 2 E 1$ wild type allele: $C Y P 2 E 1 * 1 A ; c 2(P s t I / R s a I)$ allele: $C Y P 2 E 1 * 5 B ; C$ (DraI) allele: $C Y P 2 E 1 * 6$. (http://www.imm.ki.se/CYPalleles).
}

inherited homozygous deletion of the gene [20] which has been related to ethnic variation [21].

Polymorphisms in CYP1A1, CYP2E1 and GSTM1 have been associated to an increase of cancer risk in lung, bladder, liver, pharynx, larynx, skin, rectum and colon [22-33].

In Chile the mortality rate for lung cancer has increased from 2/100 000 inhabitants in 1935 to 13/ 100000 in 1996, although the rate of mortality in some mining regions might reach $35 / 100000$. The rate of mortality for lung, bronchia and trachea is the second cause of mortality by cancer with around 1700 cases a year. Santiago, Chile which is a highly polluted city specially in winter, has recently been declared a saturated zone to ozone, carbon monoxide and particulate matter (PM10). In a previous work, we have shown that organic extracts from Santiago's airborne particles are highly mutagenic and contain high levels of carcinogenic PAHs, including benzo(a)pyrene [34-37]. In this work, we have investigated the distribution of single and combined genotypes of CYPIAl (MspI and ile/ val), CYP2E1 (C and c2) and GSTM1 in two Chilean groups (healthy controls and lung cancer). We have also studied how the associated risk for smoking related lung cancers is modified by the combination of CYP1A1, CYP2E1 and GSTM1 polymorphisms.

\section{Materials and methods}

\subsection{Study design and sample size}

In order to evaluate the relationship between genetic polymorphisms and lung cancer risk, a casecontrol study was designed. The following criteria were taken in account to calculate the sample size: (a) $15 \%$ expected frequency for the allele c2 (the less frequent allele) in the chilean population [37]; (b) CI $95 \%(1-\alpha)$; (c) a $\beta$ value of $20 \%$; (d) a relationship 1:2 between cases and controls and a risk three times higher for lung cancer for the individuals carrying unfavorable alleles in the cases. This gives a size of 122 controls and 61 cases.

\subsection{Study population}

Lung cancer patients and controls were recruited from the Santiago of Chile area. Blood samples were obtained from 174 healthy Chilean controls 
Table 1

General characteristics of the healthy control and lung cancer patient groups

\begin{tabular}{lll}
\hline & Healthy controls $(n=174)$ & Lung cancer $(n=60)$ \\
\hline Age (years) & $50.30 \pm 14.43^{\mathrm{a}}$ & $62.78 \pm 11.02^{\mathrm{a}}$ \\
Gender (M/F) & $88 / 86$ & $50 / 10$ \\
Smoking status (\%smokers) & $90(52 \%)$ & $60(100 \%)$ \\
Histological type & & Adenocarcinoma (8.30\%) \\
& & Squamous cell ca (46.9\%) \\
& & Large cell ca (17.2\%) \\
& Small cell ca $(2.10 \%)$ \\
& & Others $(10.6 \%)$ \\
& & Non-classified $(14.9 \%)$ \\
\hline
\end{tabular}

${ }^{\text {a }}$ The data are presented as mean $\pm \mathrm{SD}$.

and 60 unrelated lung cancer patients living in Santiago. Table 1 summarizes their characteristics. All samples were obtained following informed written consent, previously approved by the ethics committee. Both controls and cancer patients were interviewed regarding smoking habits, alcohol drinking, use of oral contraceptives or hormones, incidence of past records of cancer in related family members, and exposure to occupational, outdoor and indoor carcinogenic pollutants. Lung cancer patients were all previously diagnosed histologically and their medical records were available from the Hospital del Torax, Santiago. The histological type was determined only in 51 of 60 cases. The most abundant was the squamous cells, followed by the large cells. Extent of tobacco smoke exposure was assessed by smoking index $(\mathrm{SI})$ (cigarettes/day $\times 365$ ). A smoker was defined as a person with an SI of 800. Both present smokers and former smokers at the time of the analysis were considered as smokers.

\subsection{Genotyping methods}

Polymerase chain reaction (PCR) based restriction fragment length polymorphism (RFLP) was used to examine the polymorphisms of interest. DNA was isolated from peripheral blood samples, collected on EDTA [38]. All samples were submitted to separate amplifications followed by digestion with appropriate restriction enzymes.

\subsection{PCR amplification}

\subsubsection{CYPIA1}

For the MspI site, PCR amplification was carried out using previously described primers C44 and C47 [8] yielding a fragment of $340 \mathrm{bp}$. The exon 7 polymorphism (substitution of Ile 462 for val 462), was determined as previously described [39]. The downstream primer incorporated a mismatched base to engineer a NcoI restriction enzyme site in the PCR products derived from the Ile 462 allele of the gene. This restriction site was lost in the val 462 allele of the gene. A $\mathrm{NcoI}$ restriction enzyme site, located upstream of the mutation in both genotypes, served as a positive control for PCR product digestion. Fragments of 322 bp were yielded.

\subsection{2. $C Y P 2 E 1$}

For the DraI site, detection was carried out using the primers described by Hirvonen et al. [40], yielding a $373 \mathrm{bp}$ fragment. For the RsaI and PstI polymorphisms, primers yielding a 413 bp fragment [41] were used to amplify between -1372 and -960 nucleotides upstream of the gene to detect both mutations.

\subsubsection{GSTM1}

GSTM1 genetic polymorphism was determined simultaneously with MspI primers as an internal control of amplification, as described by Ambrosone et al. [42]. GSTM1 null genotype was assessed by the absence of a $273 \mathrm{bp}$ fragment, using agarose electrophoresis.

\subsection{Digestion by restriction enzymes}

The PCR products were subjected to restriction enzyme digestion at $37^{\circ} \mathrm{C}$ for $1 \mathrm{~h}$ with $M s p I$ and NcoI for CYP1A1, and DraI, RsaI and PstI for 
CYP2E1 (GIBCO BRL, Life Technologies, Inc., Gaithersburg, MD, USA). The samples were then analyzed by polyacrylamide $(6 \%)$ gel electrophoresis (Biorad Lab., Richmond, CA, USA).

\subsection{Statistical analysis}

Statistical analysis was performed by the Epi Info 6.0 and SPSS 8.0 programs. Univariate logistic regression (simple) and multivariate regression(combined) were performed. Control and cancer groups were adjusted by age and sex. The association of histological type of cancer with any single, or with combined genotypes, was estimated by the Chi-square test and Fisher's exact test.

\section{Results}

Allele distributions and frequencies for the $M s p I$ and ile/val polymorphisms in CYP1A1, DraI and RsaI/PstI in CYP2E1 and the GSTMI genotypes in healthy controls and lung cancer patients are shown in Table 2. In the Chilean healthy group, frequency of the $\mathrm{m} 2$ variant allele $(0.25)$ was higher than in Caucasians [43] and lower than in Asians [8,44]. Frequency of the val variant allele (0.33) was the highest reported, higher than in Caucasians and Asians. For
MspI and ile/val CYPlAl genotypes, the presence of variant allele was more frequent in cases than in controls (1.5-fold). Similarly, the frequency of homozygous deletions of GSTM1 loci was 1.8-fold higher in lung cancer patients. However, RsaI/PstI and DraI polymorphism frequencies were similar in both groups.

Lung cancer risk associated with polymorphisms in GSTM1 and CYP1A1 genes in reference to the wild-type genotype is shown in Table 3. For the MspI polymorphism, the heterozygous genotype was present in 53\% of cancer patients and in $27 \%$ of controls $(\mathrm{OR}=4.10, P=0.0001)$, whereas the homozygous mutant genotype was present in $18 \%$ of the cancer patients and in $11 \%$ of controls $(\mathrm{OR}=3.36, P=0.009)$. Regarding the ile/val polymorphism, the heterozygous genotype was present in $58 \%$ of cancer patients and in $43 \%$ of controls $(\mathrm{OR}=2.42, P=0.01)$, whereas the homozygous mutant genotype was present in $17 \%$ of cancer group and in $12 \%$ of controls $(\mathrm{OR}=2.57$, $P=0.057)$. The DraI heterozygous genotype was present in $38 \%$ of cancer patients and in $31 \%$ of controls $(\mathrm{OR}=1.33, P=0.39)$ whereas the homozygous mutant genotype was present in $3.5 \%$ of cancer group and in $5.4 \%$ of controls, $(\mathrm{OR}=0.69$, $P=0.65)$. The RsaI/PstI heterozygous genotypes

Table 2

Distribution and allele frequencies of CYP1A1, CYP2E1 and GSTM1 polymorphisms in chilean healthy controls and lung cancer patients ${ }^{\mathrm{a}}$

\begin{tabular}{|c|c|c|c|c|c|c|}
\hline & Group & $N$ & Genotype & & & Allele frequencies \\
\hline \multirow{3}{*}{ CYP1A1 (MspI) } & & & $\mathrm{m} 1 \mathrm{~m} 1$ & $\mathrm{~m} 1 \mathrm{~m} 2$ & $\mathrm{~m} 2 \mathrm{~m} 2$ & \\
\hline & Healthy control & 140 & 86 & 38 & 16 & $\mathrm{~m} 1=0.75, \mathrm{~m} 2=0.25$ \\
\hline & Lung cancer & 55 & 16 & 29 & 10 & $\mathrm{~m} 1=0.56, \mathrm{~m} 2=0.44$ \\
\hline \multirow[t]{3}{*}{ Ile/val } & & & ile/ile & ile/val & $\mathrm{val} / \mathrm{val}$ & \\
\hline & Healthy control & 120 & 54 & 52 & 14 & $\mathrm{Ile}=0.67, \mathrm{Val}=0.33$ \\
\hline & Lung cancer & 60 & 15 & 35 & 10 & $\mathrm{Ile}=0.54, \mathrm{Val}=0.46$ \\
\hline \multirow[t]{3}{*}{ CYP2E1 (DraI) } & & & DD & $\mathrm{CD}$ & $\mathrm{CC}$ & \\
\hline & Healthy control & 129 & 82 & 40 & 7 & $\mathrm{D}=0.79, \mathrm{C}=0.21$ \\
\hline & Lung cancer & 58 & 34 & 22 & 2 & $\mathrm{D}=0.78, \mathrm{C}=0.22$ \\
\hline \multirow[t]{3}{*}{ (Rsal/PstI) } & & & $\mathrm{c} 1 \mathrm{c} 1$ & $\mathrm{c} 1 \mathrm{c} 2$ & $\mathrm{c} 2 \mathrm{c} 2$ & \\
\hline & Healthy control & 148 & 105 & 40 & 3 & $\mathrm{c} 1=0.84, \mathrm{c} 2=0.16$ \\
\hline & Lung cancer & 59 & 45 & 14 & 0 & $\mathrm{c} 1=0.88, \mathrm{c} 2=0.12$ \\
\hline \multirow[t]{3}{*}{ GSTM1 } & & & GSTM1 (+) & & GSTM1 (-) & \\
\hline & Healthy Control & 174 & 133 & & 41 & $+=0.76,-=0.24$ \\
\hline & Lung Cancer & 58 & 33 & & 25 & $+=0.57,-=0.43$ \\
\hline
\end{tabular}

${ }^{a}$ According to the recommended nomenclature of the human polymorphic genes, CYP1A1 wild type allele: $C Y P 1 A 1 * 1 A ; M s p I$ or $m 2$ allele: CYP1A1*2A; Val allele: CYP1A1*2B. CYP2E1 wild type allele: CYP2E1*1A; c2 (PstI/RsaI) allele: CYP2E1*5B;C (DraI) allele:CYP2E1*6. 
Table 3

Lung cancer risk associated with polymorphism in GSTM1, CYP2E1 and CYP1A1 genes in reference to the wild-type genotype

\begin{tabular}{|c|c|c|c|c|c|c|c|c|}
\hline Gene & Genotype & $\begin{array}{l}\text { Can } \\
n\end{array}$ & $\%$ & $\begin{array}{l}\text { Control } \\
n\end{array}$ & $\%$ & $\mathrm{OR}_{\mathrm{c}}{ }^{\mathrm{a}}$ & CI $95 \%$ & $\begin{array}{l}\chi^{2} \\
P \text { value }\end{array}$ \\
\hline \multirow[t]{8}{*}{ CYPIA1 } & Msp1 & & & & & & & \\
\hline & $\mathrm{m} 1 / \mathrm{m} 1$ & 16 & 29.1 & 86 & 61.4 & 1.0 & & \\
\hline & $\mathrm{m} 1 / \mathrm{m} 2$ & 29 & 52.7 & 38 & 27.1 & 4.1 & $1.8-9.0$ & 0.0001 \\
\hline & $\mathrm{m} 2 / \mathrm{m} 2$ & 10 & 18.2 & 16 & 11.4 & 3.3 & $1.2-9.7$ & 0.009 \\
\hline & Ile/val & & & & & & & \\
\hline & ile/ile & 15 & 25.0 & 54 & 45.0 & 1.0 & & \\
\hline & ile/val & 35 & 58.3 & 52 & 43.3 & 2.4 & $1.1-5.3$ & 0.01 \\
\hline & $\mathrm{val} / \mathrm{val}$ & 10 & 16.7 & 14 & 11.7 & 2.5 & $0.8-7.8$ & 0.057 \\
\hline \multirow[t]{8}{*}{ CYP2E1 } & Dral & & & & & & & \\
\hline & $\mathrm{D} / \mathrm{D}$ & 34 & 58.6 & 58.60 & 63.6 & 1.0 & & \\
\hline & $\mathrm{C} / \mathrm{D}$ & 22 & 37.9 & 40 & 31.0 & 1.3 & $0.6-2.7$ & 0.390 \\
\hline & $\mathrm{C} / \mathrm{C}$ & 2 & 3.5 & 7 & 5.4 & 0.6 & $0.09-3.9$ & 0.650 \\
\hline & Rsal/Pst1 & & & & & & & \\
\hline & $\mathrm{c} 1 / \mathrm{c} 1$ & 45 & 76.3 & 105 & 71.0 & 1.0 & & \\
\hline & $\mathrm{c} 1 / \mathrm{c} 2$ & 14 & 23.7 & 40 & 27.0 & 0.8 & & 0.570 \\
\hline & $\mathrm{c} 2 / \mathrm{c} 2$ & 0 & 0.0 & 3 & 2.0 & - & $0.3-1.7$ & $0.340^{\mathrm{b}}$ \\
\hline \multirow[t]{2}{*}{ GSTM1 } & $\operatorname{GSTM1}(+)^{\mathrm{c}}$ & 33 & 56.9 & 133 & 76.4 & 1 & & \\
\hline & $\operatorname{GSTM1}(-)^{\mathrm{d}}$ & 25 & 43.1 & 41 & 23.6 & 2.46 & $1.3-4.8$ & 0.004 \\
\hline
\end{tabular}

were present in $24 \%$ of cancer patients and in $27 \%$ of controls ( $\mathrm{OR}=0.82, P=0.57)$ whereas the homozygous mutant genotype was absent in the cancer group and present in $2 \%$ of controls; the $P$ value obtained through the Fischer exact test (to evaluate small samples or absence of one in the comparison matrix values) was 0.34 . The null GSTM1 genotype was found in $43 \%$ of cases and $24 \%$ of controls; the OR was $2.46(P=0.004)$.

The estimated relative risks for lung cancer in Chilean patients associated to single or combined CYP1A1, CYP2E1 and GSTM1 genotypes are shown in Table 4. The OR values related to the presence of variant alleles were 2.41 for $\mathrm{m} 2$ and 1.69 for val. The odds ratios ranged between 1.70 and 6.28 for all combinations between CYPIAl and GSTM1 polymorphisms and were lower when the variant alleles of these polymorphisms were combined with $C Y P 2 E 1$ variant alleles. The risk was higher in individuals with combined $\mathrm{m} 2$ and val alleles $(\mathrm{OR}=6.28)$. The $\mathrm{m} 2$ and $\operatorname{GSTM1}(-)$ combination showed a higher risk than each separate allele. However, the combination val/GSTM1(-) showed a lower OR value (1.70, not significant) than each separate allele. The lowest observed OR value was for the combination of val and c2 alleles with an $\mathrm{OR}=0.48$, not significant.

In order to control the confounding factor 'smoking habit', a stratified analysis was performed. Table 5 displays the single and combined effects of genotypes only in smokers from healthy control and lung cancer groups, since non-smokers had no significant statistics (null risk, data not shown). The ORs for single genotypes were $4.37,4.05$ and 3.47 for $\mathrm{m} 2$, val and GSTM1(-), respectively, and for combined genotypes were: $\mathrm{m} 2 / \mathrm{val} \mathrm{OR}=7.38$ and $\mathrm{m} 2 / \operatorname{GSTM1}(-)$, $\mathrm{OR}=3.68$. For the $\mathrm{C} / \mathrm{c} 2$ combined genotypes the OR value was 0.59 (not significant). These results, in which cigarette smoking has been controlled as a confounding factor, clearly show that lung cancer risk is mostly related to the presence of unfavorable genotypes which might give an estimation of the individual response to carcinogen exposure. All these results suggest that the balance of altered genotypes in CYP1A1 and GSTM1 will determine the response of Chileans to PAHs exposure. 
Table 4

Single or combined CYP1A1, CYP2E1 and GSTM1 genotypes and estimated relative risk for lung cancer in Chilean patients adjusted by age and sex

\begin{tabular}{|c|c|c|c|c|c|}
\hline Single or combined genotype ${ }^{a}$ & $\begin{array}{l}\text { Cases } \\
n\end{array}$ & $\begin{array}{l}\text { Controls } \\
n\end{array}$ & $\mathrm{OR}_{\mathrm{a}}^{\mathrm{b}}$ & $95 \% \mathrm{CI}$ & $\begin{array}{l}\chi^{2} \\
P \text { value }\end{array}$ \\
\hline $\mathrm{m} 2$ & 39 & 54 & 2.41 & $1.48-3.93$ & 0.0001 \\
\hline Val & 45 & 66 & 1.69 & $1.05-2.72$ & 0.009 \\
\hline GSTM1(-) & 25 & 41 & 2.46 & $1.25-4.82$ & 0.004 \\
\hline $\mathrm{C}$ & 24 & 47 & 1.16 & $0.65-2.08$ & 0.519 \\
\hline $\mathrm{c} 2$ & 14 & 43 & 0.71 & $0.35-1.41$ & 0.438 \\
\hline $\mathrm{m} 2 / \mathrm{val}$ & 24 & 15 & 6.28 & $2.39-18.34$ & 0.0001 \\
\hline m2/GSTM1(-) & 16 & 17 & 3.56 & $1.38-9.83$ & 0.0004 \\
\hline $\mathrm{m} 2 / \mathrm{c} 2$ & 9 & 12 & 2.00 & $0.37-9.54$ & 0.12 \\
\hline $\mathrm{m} 2 / \mathrm{C}$ & 11 & 15 & 1.39 & $0.49-4.82$ & 0.49 \\
\hline val/GSTM1(-) & 8 & 11 & 1.70 & $0.74-4.88$ & 0.06 \\
\hline $\mathrm{val} / \mathrm{c} 2$ & 3 & 15 & 0.48 & $0.25-1.72$ & 0.17 \\
\hline $\mathrm{val} / \mathrm{C}$ & 9 & 18 & 1.45 & $0.55-3.67$ & 0.48 \\
\hline $\mathrm{C} / \mathrm{c} 2$ & 9 & 31 & 0.56 & $0.19-1.46$ & 0.19 \\
\hline C/GSTM1(-) & 6 & 8 & 3.01 & $0.49-19.4$ & 0.07 \\
\hline c2/GSTM1(-) & 7 & 5 & 2.54 & $0.40-18.55$ & 0.20 \\
\hline
\end{tabular}

${ }^{\text {a }}$ Rare alleles are considered either including heterozygous or homozygous.

${ }^{\mathrm{b}} \mathrm{OR}_{\mathrm{a}}$, adjusted odds ratios.

\section{Discussion}

In this work CYP1A1, CYP2E1 and GSTM1 genotypes have been analyzed in 60 Chilean lung cancer patients and 174 healthy controls. The frequencies of $\mathrm{m} 2$ and val alleles in CYPIAl and the null genotype for GSTM1 were higher in lung cancer patients whereas frequencies for $\mathrm{C}$ and $\mathrm{c} 2$ alleles in the CYP2E1 gene were not significantly different.
Contradictory data have been published concerning CYP1A1 and CYP2E1 polymorphisms and their relationships with lung cancer susceptibility $[13,45,46]$. For example, no association was found between CYP1A1 polymorphisms and lung cancer in Caucasians while Asians showed associations limited to the homozygous recessive MspI genotype or the heterozygous exon 7 genotype [45]. An association between CYPIAl hyperinducibility and lung cancer was

Table 5

Risk analysis for single and combined CYP1A1, CYP2E1 and GSTM1 genotypes and lung cancer in smokers from healthy control and lung cancer groups, adjusted by age and $\operatorname{sex}^{\mathrm{a}}$

\begin{tabular}{|c|c|c|c|c|c|}
\hline Single or combined genotype ${ }^{b}$ & $\begin{array}{l}\text { Cases } \\
n\end{array}$ & $\begin{array}{l}\text { Controls } \\
N\end{array}$ & $\mathrm{OR}_{\mathrm{a}}^{\mathrm{c}}$ & $95 \% \mathrm{CI}$ & $\begin{array}{l}\chi^{2} \\
P \text { value }\end{array}$ \\
\hline$m 2$ & 39 & 26 & 4.37 & $1.78-10.82$ & 0.0003 \\
\hline Val & 45 & 36 & 4.05 & $1.54-8.37$ & 0.0017 \\
\hline C & 24 & 27 & 1.07 & $0.44-3.01$ & 0.55 \\
\hline$c 2$ & 14 & 22 & 0.78 & $0.23-2.73$ & 0.80 \\
\hline $\operatorname{GSTM1}(-)$ & 25 & 17 & 3.47 & $1.53-13.29$ & 0.001 \\
\hline $\mathrm{m} 2 / \mathrm{val}$ & 24 & 7 & 7.38 & $2.79-26.3$ & 0.00002 \\
\hline m2/GSTM1( - ) & 16 & 8 & 3.68 & $1.31-10.40$ & 0.003 \\
\hline$C / c 2$ & 9 & 20 & 0.59 & $0.09-5.67$ & 0.12 \\
\hline
\end{tabular}

\footnotetext{
${ }^{\text {a }}$ Some combinations were not analyzed because of the small number of individuals carrying both rare alleles.

${ }^{\mathrm{b}}$ Rare alleles are considered as heterozygous or homozygous.

${ }^{\mathrm{c}} \mathrm{OR}_{\mathrm{a}}$, adjusted odds ratios.
} 
reported [3-5], but not between $C Y P 1 A 1$ hyperinducibility and MspI polymorphism in Caucasians [4]. However, most of the studies performed in Caucasians have not been large enough to compensate for the very low frequency of the $\mathrm{m} 2$ allele in this population compared to Asians. Another reason for these discrepancies could be related to differences in linkage or genetic associations between alleles in different populations as shown in Africans which display no linkage between $M s p I$ and Ile-val polymorphisms in contrast to Asians or Caucasians [47].

In a previous work [37] we have reported that frequencies of $\mathrm{m} 2$ and val alleles were three and five times higher in a healthy Chilean control group than in a healthy French control group, whereas the frequency for the null genotype for GSTM1 was almost half as high as in the French group. Although in the Chilean healthy group the frequency of the $\mathrm{m} 2$ allele was higher than in Caucasians, it was lower than in Asians [8]. On the other hand, the frequency of the val allele in the Chilean healthy group was the highest reported, higher than for Caucasians, Africans and Asians [8]. Therefore, as shown by Garte et al. [10] and Kihara et al. [48], CYP1Al and GSTM1 mutations vary among ethnic groups.

In Chileans, the genotypes most associated to the lung cancer were those of Mspl polymorphism $(\mathrm{m} 1 \mathrm{~m} 2: \mathrm{OR}=4.10, P=0.0001 ; \mathrm{m} 2 \mathrm{~m} 2: \mathrm{OR}=3.36$, $P=0.009)$ and the presence of the null genotype of GSTM1 gene $(\mathrm{OR}=2.46, P=0.004)$. According to the literature, a higher frequency of the null genotype for GSTM1 in lung cancer patients was found, suggesting that the deletion of the GSTM1 gene causes the loss of detoxification of the ultimate carcinogen resulting in higher risk for lung cancer. In addition, our data suggest an association between GSTM1( - ) or MspI polymorphisms and squamous cell carcinoma, as recently reported [49]. The association values found for GSTMI and MspI were close to significant $\left(\chi^{2}=3.12, P=0.08\right.$ and $2.26, P=0.013$, respectively).

The estimated relative risk for combined unfavorable genotypes was particularly high for combined $m 2$ and val variant alleles in CYPIAl $(\mathrm{OR}=6.28$, $P=0.0001)$. The enzyme expressed from the val type has been described as presenting higher activity and mutagenicity towards benzo(a)pyrene than that corresponding to the ile type [50]. These observations might indicate that the val CYPIAl genotype could increase and/or activate procarcinogens resulting in higher risk for lung cancer. Although lower, the estimated relative risk for the combination between the null genotype for GSTM1 and $\mathrm{m} 2$ variant allele in CYPlAl was still high $(\mathrm{OR}=3.56, P=0.008)$. Association between hyperinducibility and GSTM1 deletion was shown to highly increase risk of lung cancer [5].

Cigarette smoking enhanced the association between lung cancer and unfavorable polymorphisms in CYP1A1 and GSTM1 genes. The OR values for the mutated alleles in smokers showed that the major cancer risk was for individuals carrying unfavorable genotypes. These results suggest that the presence of altered CYP1A1 and GSTM1 genotypes in Chilean smokers makes these individuals at higher risk for lung cancer. The highest odds ratio was observed for smokers carrying $\mathrm{m} 2$ and val alleles $(\mathrm{OR}=7.38$, $P=0.00002$ ) suggesting that smokers presenting both mutations might have higher capacity of CYPlAl gene transcriptions and hence higher capacity for carcinogen activation. Stücker et al. [5] recently reported that there was no interaction between smoking and CYPIAl inducibility.

The frequency of CYPIAl altered genotypes in the Chilean studied groups suggests that Chilean individuals might be more susceptible to PAHs exposures than Caucasian and Afro-American groups, although this will depend on the balance of unfavorable genotypes including other polymorphic enzymes in each ethnia. This might be important in relationship to smoking and exposure to urban PAHs adsorbed in particulate matter. Almost $40 \%$ of the Chilean population live in Santiago and this city has shown elevated mutagenicity and high levels of carcinogenic PAHs in outdoor airborne particles [34-36] thus possibly representing a high risk for lung cancer to Santiago inhabitants.

Our results suggest that the Chilean population, which represents different degrees of mixture between native Americans and Caucasians (mostly Spaniards), shows genetic polymorphisms in metabolic genes which are closer, although different from Asians and might be important in lung cancer susceptibility. Recently, Taioli et al. [33] found a significant increased risk for lung adenocarcinoma among people carrying the CYP1A1- $\mathrm{m} 3$ polymorphism, although they did not observe any association of the Afro- 
American specific polymorphism with overall lung cancer risk. They observed that subjects carrying the m3 polymorphism smoked significantly less than patients without this mutation, suggesting that some polymorphisms in metabolic genes might play an important role in cancer risk at low levels of PAHs exposure. Although this mutation is present only in Afro-Americans, and might not be present in Chileans, from a public health point of view, this example might be relevant if a similar effect is observed for other genotypes, since a large part of the general population is exposed to low levels of environmental carcinogens and the frequencies of polymorphisms in metabolic genes are relatively high compared to single cancer susceptibility genes.

Our data, in addition to evaluating lung cancer risk in the Chilean population, might help to understand inter-ethnic differences in the distribution of polymorphic enzymes as well as the function of simultaneous polymorphisms in metabolic genes in each subject and lung cancer susceptibility. To our knowledge, this is the first study relating CYP1A1, CYP2E1 and GSTM1 gene polymorphisms with lung cancer risk in a Chilean population, a region where environmental and ethnical factors might play an important role in the etiology of the disease.

\section{Acknowledgements}

This research was financed by grants: European Community INCO, Contract No. IC18-CT98-0341, ALFA-OMET Contract No. ALR/B7-3011/94.045.0059.2, and Fondecyt No. 2950034. We thank Brigitte Simon for her excellent assistance in part of this work and Dr Alvaro Undurraga from Hospital del Tórax for his collaboration to obtain blood samples from patients.

\section{References}

[1] D. Nebert, D.D. Petersen, A. Puga, Human Ah locus polymorphism and cancer: inducibility of CYP1A1 and other genes by combustion products and dioxin, Pharmacogenetics 1 (1991) 68-78.

[2] V. Daniel, Glutathione S-transferases: gene structure and regulation of expression, Crit. Rev. Biochem. Mol. Biol. 28 (1993) 173-207.

[3] R. Kouri, C. McKinney, D. Slomiany, D. Snodgrass, N. Wray,
T. McLmore, Positive correlation between high aryl hydrocarbon hydroxylase activity and primary lung cancer as analyzed in cryopreserved lymphocytes, Cancer Res. 42 (1982) 5030-5037.

[4] M. Jacquet, V. Lambert, E. Baudoux, M. Muller, P. Kremers, J. Gielen, Correlation between P450 CYP1A1 inducibility, Msp1 genotype and lung cancer incidence, Eur. J. Can 32A (1996) 1701-1706.

[5] I. Stücker, M. Jacquet, I. de Waziers, S. Cénée, Ph. Beaune, P. Kremers, D. Hémon, Relation between inducibility of CYP1A1, GSTM1 and lung cancer in a French population, Pharmacogenetics 10 (2000) 617-627.

[6] K. Kawajiri, J. Watanabe, O. Gotoh, Y. Tagashira, K. Sowaga, Y. Fujii-Kuriyama, Structure and drug inducibility of human cytochrome P450c gene, Eur. J. Biochem. 159 (1986) 219225.

[7] K. Kawajiri, K. Nakachi, K. Imai, A. Yoshü, N. Shinada, J. Watanabe, Identification of genetically high risk individuals to lung cancer by DNA polymorphisms of the cytochrome P4501A1 gene, FEBS Lett. 263 (1990) 131-133.

[8] S. Hayashi, J. Watanabe, K. Nakachi, K. Kawajiri, P.C.R. detection, of an A/G polymorphism within exon 7 of the CYP1A1 gene, Nucleic Acids res 19 (1991) 4797.

[9] F. Crofts, G.N. Cosma, D. Currie, E. Taioli, P. Toniolo, S.J. Garte, A. novel, CYP1A1 gene polymorphism in AfricanAmericans, Carcinogenesis 14 (1993) 29-31.

[10] S. Garte, J. Trachman, F. Crofts, P. Toniolo, J. Buxbaum, S. Bayo, E. Taioli, Distribution of composite CYP1A1 genotypes in africans, african-americans and caucasians, Hum. Hered. 46 (1996) 121-127.

[11] L. Cascorbi, J. Brockmoller, L. Roots, A C4887A polymorphism in exon 7 of human CYP1A1: population frequency, mutation linkages and impact on lung cancer susceptibility, Cancer Res. 56 (1996) 4965-4969.

[12] A.S. Aynacioglu, I. Cascorbi, P.M. Ozikiewicz, I. Roots, High frequency of CYP1A1 mutations in a Turkish population, Arch. Toxicol. 72 (1998) 215-218.

[13] R.S. Houlston, CYP1A1 polymorphisms and lung cancer risk: a meta-analysis, Pharmacogenetics 10 (2000) 105-114.

[14] I. Johansson, M. Ingelman-Sundberg, Benzene metabolism by ethanol acetone and benzene inducible cytochrome P-450 IIE1 in rat and rabbit liver microsomes, Cancer Res. 48 (1988) 5387-5390.

[15] P. Thomas, S. Bandiera, S. Maines, D. Ryan, W. Levin, Regulation of cytochrome P-450j a high-affinity N-nitrosodimethylamine demethylase, in rat hepatic microsomes, Biochemistry 26 (1987) 2280-2289.

[16] C. Yang, J. Yoo, H. Ishizaki, J. Hong, Cytochrome P450IIE1: roles in nitrosamine metabolism and mechanism of regulation, Drug. Metabol. Rev 22 (1990) 147-159.

[17] F. Guengerich, D. Kim, M. Iwasaki, Role of human cytochrome P450IIE1 in the oxidation of many low molecular weight cancer suspects, Chem. Res. Toxicol. 4 (1991) 158178.

[18] A. Rannug, A. Alexandrie, I. Persson, M. Ingelman-Sundberg, Genetic polymorphism of cytochromes P450 1A1, 2D6 and 2E1: regulation and toxicological significance, J. Occup. Med. 37 (1995) 25-36. 
[19] S. Harada, M. Abbey, M. Tanaka, D. Agarwal, H. Goedde, Liver glutathione S-transferase polymorphisms in Japanese and its pharmacogenetic importance, Human Genet. 75 (1987) 322-325.

[20] J. Seidegard, W.R. Vorachek, R.W. Pero, W.R. Pearson, Hereditary differences in the expression of the human glutathione transferase active on trans-stilbene oxide are due to a gene deletion, Proc. Natl. Acad. Sci. USA 85 (1998) 7293-7297.

[21] H.J. Lin, C.-Y. Han, D.A. Bernstein, W. Hsiao, B.K. Lin, S. Hardy, Ethnic distribution of the glutathione transferase Mu 11 (GSTM1) null genotype in 1473 individuals and application to bladder cancer susceptibility, Carcinogenesis 15 (1994) 1077-1081.

[22] F. Uematsu, H. Kikuchi, T. Ohmachi, I. Sagami, M. Motomiya, Y. Kamataki, Two common RFLPs of the human CYP2E gene, Nucleic Acids Res. 19 (1991) 2803.

[23] S. London, A. Daly, J. Cooper, C. Carpenter, W. Navidi, L. Ding, J. Idle, Lung cancer risk in relation to the CYP2E1 RsaI genetic polymorphism among african-americans and caucasians in Los Angeles Country, Pharmacogenetics 6 (1996) 151-158.

[24] M. Yu, A. Gladek-Tarborough, S. Chiamprasert, R. Santella, Y. Liaw, C. Chen, Cytochrome P450 2E1 and glutathione Stransferase M1 polymorphisms and susceptibility to hepatocellular carcinoma, Gastroenterology 109 (1995) 1266-1273.

[25] M. Tsutsumi, Y. Matsuda, A. Takada, Role of ethanol-inducible cytochrome P-450 2E1 in the development of hepatocellular carcinoma by the chemical carcinogen, N-nitrosodimethylamine, Hepatology 18 (1993) 1483-1489.

[26] M. Ingelman-Sundberg, I. Johansson, H. Yin, Y. Terelius, E. Eliasson, P. Clot, Ethanol-inducible cytochrome P4502E1: genetic polymorphism, regulation, and possible role in the etiology of alcohol-induced liver disease, Alcohol 10 (1993) 447-452.

[27] D. Bell, J. Taylor, D. Paulson, C. Robertson, J. Mohler, G. Lucier, Genetic risk and carcinogen exposure: a common inherited defect of the carcinogen-metabolism gene glutathione S-transferase M1 (GSTM1) that increases the susceptibility to bladder cancer, J. Natl. Cancer Inst. 85 (1993) 1159-1164.

[28] G.I. Murray, P.J. Paterson, R.J. Weaver, S.W.B. Ewen, W.T. Melvin, M.D. Burke, The expression of cytochrome P-450, epoxide hydrolase, and glutathione s-transferase in hepatocellular carcinoma, Cancer 71 (1993) 36-43.

[29] J. Tanita, S. Tsuchida, J. Hozawa, K. Sato, Expression of glutathione s-transferase-p in human squamous cell carcinomas of the pharynx and larynx, Cancer 72 (1993) 569-576.

[30] A.K. Alexandrie, M.1. Ingelman-Sunberg, J. Seidegard, G. Tornlin, A. Rannug, Genetic susceptibility to lung cancer with special emphasis on CYP1A1 and GSTM1: a study on host factors in relation to age at onset, gender and histological cancer types, Carcinogenesis 15 (1994) 1785-1790.

[31] A. Heagerty, D. Fitzgerald, A. Smith, B. Bowers, P. Jones, A. Fryer, L. Zhao, J. Alldersea, R. Strange, Glutathione S-transferase GSTM1 phenotypes and protection against cutaneous malignancy, Lancet 343 (1994) 266-268.
[32] C.E. Szarka, G.R. Pfeiffer, S.T. Hum, L.C. Everley, A.M. Balshem, D.F. Moore, Glutathione s-transferase activity and glutathione s-transferase mu expression in subjects with risk for colorectal cancer, Cancer Res. 55 (1995) 2789-2793.

[33] E. Taioli, J. Ford, J. Trachman, Y. Li, R. Demopoulos, S. Garte, Lung cancer risk and CYP1A1 genotype in African Americans, Carcinogenesis 19 (1998) 813-817.

[34] M. Adonis, L. Gil, Polycyclic aromatic hydrocarbons levels and mutagenicity of inhalable particulate matter in Santiago, Chile. Inhalation Toxicol. 12 (2000) 1173-1183.

[35] L. Gil, M. Adonis, Polycyclic aromatic hydrocarbons levels and mutagenic activities of organic extracts from airborne particles in santiago of Chile, Indoor + Built Environ. 5 (1996) 155-164.

[36] L. Gil, L. King, M. Adonis, Trends of polycyclic aromatic hydrocarbons levels and mutagenicity in Santiago's Inhalable airborne particles in the period 1992 -1996, Inhalation Toxicol. 12 (2000) 1185-1204.

[37] L. Quiñones, F. Berthou, N. Varela, B. Simon, L. Gil, D. Lucas, "Ethnic susceptibility to lung cancer: differences in CYP2E1, CYP1A1 and GSTM1 genetic polymorphisms between French Caucasian and Chilean Populations", Cancer Lett. 141 (1999) 167-171.

[38] D. Lucas, C. Ménez, C. Girre, F. Berthou, P. Bodenez, I. Joannet, E. Hispard, L. Bardou, J. Ménez, Cytochrome P4502E1 genotype and chlorzoxazone metabolism in healthy and alcoholic caucasian subjects, Pharmacogenetics 5 (1995) 298-304.

[39] A. Cantlay, D. Lamb, M. Gillooly, J. Norman, D. Morrison, C.A.D. Smith, Association between the CYP1A1 gene polymorphism and susceptibility to emphysema and lung cancer, J. Clin. Pathol. Mol. Pathol. 48 (1995) M210-M214.

[40] A. Hirvonen, K. Husgafuel-Pursiainen, S. Anttila, A. Karjailainen, H. Vainio, The human CYP2E1 gene and lung cancer: DraI and RsaI restriction fragment length polymorphisms in a Finnish study population, Carcinogenesis 14 (1993) 85-88.

[41] S. Hayashi, J. Watanabe, K. Kawajiri, Genetic polymorphisms in the $5^{\prime}$-Flanking region change transcriptional regulation of the human cytochrome P450IIE1 gene, J. Biochem. 110 (1991) 559-565.

[42] C. Ambrosone, J. Freudenheim, S. Oraham, J. Marshall, J. Vena, J. Brasure, R. Laughlin, T. Nemoto, A. Michalek, A. Harrington, T. Ford, P. Shields, Cytochrome P4501A1 and Glutathione S-transferase (Ml) genetic polymorphisms and postmenopausal breast cancer risk, Cancer Res. 55 (1995) 3483-3485.

[43] D. Lucas, C. Menez, F. Floch, Y. Gourlaouen, O. Sparfel, I. Joannet, P. Bodénez, J. Jezequel, F. Berthou, L. Bardou, J. Ménez, Cytochrome P4502E1 and P4501A1 genotypes and susceptibility to cirrhosis or upper digestive tract cancer in alcoholic caucasians, Alcohol Clin. Exp. Res. 20 (1996) 1033-1037.

[44] E. Stephens, J. Taylor, N. Kaplan, C. Yang, L. Hsieh, G. Lucier, D. Bell, Ethnic variation in the CYP2E1 gene: polymorphism analysis of 695 African-Americans, EuropeanAmericans and Taiwanese, Pharmacogenetics 4 (1994) 58-63. 
[45] A. d'Errico, E. Taioli, X. Chen, P. Vineis, Genetic metabolic polymorphisms and the risk of cancer: a review of the literature, Biomarkers 1 (1996) 149-173.

[46] N. Wong, F. Rae, K.J. Simpson, G.D. Murray, D.J. Harrison, Genetic polymorphisms of cytochtome P4502E1 and susceptibility to alcoholic liver disease and hepatocellular carcinoma in a white population: a study and literature review, including meta-analysis. , J. Clin. Pathol: Mol. Pathol. 53 (2000) 88-93.

[47] S. Garte, The role of ethnicity in cancer susceptibility gene polymorphisms: the example of CYP1A1, Carcinogenesis 19 (1998) 1329-1332.

[48] M. Kihara, M. Kihara, K. Noda, Risk of smoking for squa- mous and small cell carcinomas of lung modulated by combinations of CYP1A1 and GSTM1 gene polymorphisms in Japanese population, Carcinogenesis 16 (1995) 2331-2336.

[49] L. Le Marchand, L. Sivaraman, L. Pierce, A. Seifried, A. Lum, L.R. Wilkens, A.F. Lau, Associations of CYP1A1, GSTM1 and CYP2E1 polymorphisms with lung cancer suggest cell type specificities to tobacco carcinogens, Cancer Res. 58 (21) (1998) 1858-1863.

[50] S.I. Hayashi, J. Watanabe, K. Kawajiri, High susceptibility to lung cancer analyzed in terms of combined genotypes of P450IA1 and Mu-class glutathione s-transferase genes, Jpn. J. Cancer Res. 83 (1992) 866-870. 